\title{
CONFIANÇA, COMPORTAMENTO OPORTUNISTA E QUEBRA DE CONTRATOS NA CADEIA PRODUTIVA DO TABACO
}

\section{TRUST AND OPPORTUNISTIC BEHAVIOR: THE BREACH OF CONTRACTS IN THE TOBACCO CHAIN}

Data de submissão: 17/02/2014 Aceite: 20/05/2016

Heron Sergio Moreira Begnis ${ }^{1}$ Silvio Cesar Arend ${ }^{2}$ Rejane Maria Alievi ${ }^{3}$

\section{RESUMO}

Baseado na Economia dos Custos de Transação e na literatura sobre as relações interorganizacionais, este artigo tem como objetivo analisar as características socioeconômicas dos produtores que podem estar relacionadas ao comportamento oportunista e à quebra de contrato na cadeia produtiva do tabaco no Sul do Brasil. Esta pesquisa possui um caráter predominantemente quantitativo, e os dados foram coletados através de uma survey envolvendo os produtores de tabaco dos três estados do Sul do Brasil. A análise apontou as principais características distintivas dos produtores de tabaco mais propensos a quebrar seus contratos com as empresas integradoras.

Palavras-chave: Contratos; Sistema Integrado de Produção (SIP); Oportunismo; Tabaco.

\footnotetext{
1 Possui graduação em Ciências Econômicas pela Universidade de Santa Cruz do Sul. Mestrado em Economia Rural pela Universidade Federal do Rio Grande do Sul. Doutorado em Agronegócios pela Universidade Federal do Rio Grande do Sul. Atualmente é professor da Universidade de Santa Cruz do Sul atuando no Mestrado Profissional em Administração como docente do quadro permanente. Santa Cruz do Sul. Rio Grande do Sul. Brasil. E-mail: heron@unisc.br 2 Possui Graduação em Ciências Econômicas pela Faculdade de Ciências Contábeis e Administrativas de Santa Cruz do Sul, FACCOSUL. Mestrado em Economia pela Universidade Federal do Rio Grande do Sul, UFRGS. Doutorado em Economia pela Universidade Federal do Rio Grande do Sul, UFRGS. Santa Cruz do Sul. Rio Grande do Sul. Brasil. E-mail: silvio@unisc.br

3 Possui Graduação em Ciências Econômicas. Mestrado em Economia, na área de Economia Industrial, pela Universidade Federal do Rio Grande do Sul (UFRGS). Doutorado em Administração, na área de Gestão da Tecnologia e Produção, pela Universidade Federal do Rio Grande do Sul (UFRGS). Atualmente é Professora Adjunta do Departamento de Ciências Econômicas e Administrativas da Universidade de Santa Cruz do Sul. Santa Cruz do Sul. Rio Grande do Sul. Brasil. E-mail: ralievi@unisc.br
} 


\begin{abstract}
This study aimed to analyze the growers' socioeconomic characteristics that are related to opportunistic behavior and contract breach in the tobacco productive chain in South Brazil. The nature of this research is predominantly quantitative and the data were collected through a survey with tobacco growers from the three states of South Brazil. Based on the literature of Transaction Costs Economics and inter-organizational relations, the analysis showed the main characteristics of the tobacco growers who are more likely to breach their contracts with the integrative companies.
\end{abstract}

Keywords: Contract Breach; Integrated Production System (IPS); Opportunism; Tobacco.

\title{
1 INTRODUÇÃO
}

A produção de tabaco no Brasil ocorre com base em um Sistema Integrado de Produção (SIP) cujo mecanismo básico é o contrato de integração. Esse contrato, de acordo com Begnis, Estivalete e Pedrozo (2007), estabelece o elemento-chave das relações contratuais entre fumicultor e indústria: o compromisso da comercialização exclusiva do tabaco cultivado pelo produtor para a empresa, em contrapartida ao compromisso da indústria em adquirir toda a produção contratada.

Na cultura do tabaco, o SIP é responsável pela coordenação da cadeia produtiva, direcionando a produção de acordo com as exigências dos mercados compradores e colocando, através das melhores práticas de produção, o tabaco brasileiro em um patamar competitivo mais elevado em termos internacionais. Disso resulta que as sucessivas quebras contratuais colocam em risco o sistema integrado, de modo que o Brasil poderia deixar de ser o maior exportador mundial de tabaco em folha e os investimentos poderiam migrar para outras regiões do globo, em busca de tabacos com as características demandadas pelo mercado (BEGNIS; ESTIVALETE; PEDROZO, 2007).

A quebra contratual é analisada por autores como Pinheiro e Saddi (2006), que procuram identificar alguns princípios gerais que condicionam a eficiência dos contratos, a qual depende da presença de uma estrutura de incentivos que leve as partes a cumprir as obrigações e promessas fixadas entre elas no momento da assinatura do contrato. Para Rezende e Zylbersztajn (2011, p. 156), "por quebras contratuais entende-se a falha total ou parcial na entrega do produto contratado", assunto a ser abordado neste estudo.

Frente a essa questão, os resultados da pesquisa podem colaborar para que as organizações envolvidas na coordenação da cadeia produtiva do tabaco adotem medidas para reforçar o sistema integrado de produção, cuja importância é reconhecida pelas entidades representativas dos agricultores (Associação dos Fumicultores do Brasil - Afubra) e pela indústria beneficiadora (Sindicato da Indústria do Tabaco - Sinditabaco). Identificar a relação existente entre o perfil dos produtores e o comportamento destes com relação aos contratos seria um importante ponto de partida, pois o comportamento oportunista pode levar a um resultado coletivo menos satisfatório ou até mesmo indesejável, podendo causar a desarticulação do sistema integrado de produção.

Cabe ainda destacar que a produção de tabaco no Brasil ocorre quase que exclusivamente em pequenas propriedades rurais, ocupando mão de obra familiar. Na safra de 2007/2008, segundo o Anuário Brasileiro do Fumo (2007), a produção de tabaco envolvia aproximadamente 182 mil produtores integrados, distribuídos em 780 municípios nos três estados do Sul do Brasil, gerando uma renda superior a $\mathrm{R} \$ 3$ bilhões. 


\section{RELAÇÕES CONTRATUAIS E OPORTUNISMO DOS AGENTES}

\subsection{Racionalidade limitada e oportunismo}

A Teoria dos Custos de Transação, referida pela primeira vez em um artigo publicado por Coase em 1937, intitulado "The Nature of the Firm", promoveu um novo entendimento, uma nova concepção sobre a formação dos custos. Até a publicação de Coase, as análises sobre a Teoria da Firma centravam os estudos das organizações na ótica de maximização de lucros em busca de minimizar custos na função de produção das firmas. Para Coase (1937), o custo de transação é representado por todos os custos que em firma incorrem no processo de ida ao mercado. Nessa ida ao mercado, englobam os custos que fazem parte de negociação, contratos, ou seja, todos os custos envolvidos no processo de organização das atividades produtivas. A partir da evolução teórica da contribuição de Coase, Williamson, na década de 1970, avançou nos estudos sobre os Custos de Transação. Nos estudos de Williamson (2002), esses custos passam a ser entendidos além das variáveis que são encontradas no funcionamento do mercado. Nessa nova concepção, são diferentes para cada firma, para cada transação, para cada ida ao mercado (FIANI, 2013). A forma de organização da produção e a maneira como os produtos chegam no mercado para sua validação apresentam especificidades distintas. Estas especificidades é que diferenciam as empresas e as levam a diferentes patamares competitivos.

Partindo da nova abordagem teórica da formação dos custos de transação, os agentes econômicos, as empresas, caracterizam-se, entre outros fatores, pela sua capacidade adaptativa e aprendizado, de modo que a influência social modifica a forma como esses agentes tomam decisões racionais. De acordo com Williamson (2002), o estudo das estruturas de governança (mecanismo de tomada de decisões pelas organizações) não deve ignorar a percepção da racionalidade limitada, tal como tratada por Simon $(1997,2000)$, e a influência do ambiente sobre as escolhas racionais (SIMON, 1956). Assim, todos os contratos seriam inevitavelmente incompletos (Williamson, 2002), sendo que adaptações e ajustes são necessários frente aos possíveis distúrbios. Os distúrbios citados pelo autor referem-se às diferentes variáveis que podem ocorrer em todas as etapas de produção até a ida de cada produto ao mercado. Cada agente econômico, ainda que atue no mesmo mercado competitivo, apresenta diferentes custos de transação, pois os agentes estão sujeitos não apenas às necessidades de adaptações contratuais em virtude dos imprevistos (decorrentes da própria racionalidade limitada), mas também ao comportamento estratégico (oportunista) que resulta na quebra contratual. Nestes casos, os esforços de proporcionar um ordenamento privado atuam no sentido de promover estruturas de governança que diminuem a possibilidade de impasses e quebras de contratos.

Todo contrato envolve dependência bilateral, de modo que os problemas surgem quando investimentos não realocáveis são feitos (WILLIAMSON, 1998). Em virtude disso, os agentes devem estar preparados para realizar adaptações cooperativas nos seus contratos. Surgem, então, os conceitos de compromissos críveis e alinhamentos discriminatórios, que sinalizam para tipos diferentes de estruturas de governança. É justamente nesse sentido que se dá a contribuição da Economia dos Custos de Transação (ECT). Dentro dessa perspectiva, Williamson (1985) distingue níveis diferentes de racionalidade. Embora os agentes econômicos ajam de forma maximizadora, sua capacidade cognitiva é limitada. Em confronto com a realidade da racionalidade, os custos de planejamento, adaptação e motivação das transações necessitam ser expressamente considerados. Ainda segundo Williamson (1985), esses diferentes níveis de racionalidade estão 
associados a diversas formas de comportamento baseado no interesse próprio, cuja forma mais forte é o oportunismo. O oportunismo, segundo a concepção de Williamson (1985), significa o comportamento baseado na esperteza.

Aplicando essa lógica às decisões econômicas regidas por contratos tanto implícitos como formais, a realidade mostra que, em diferentes momentos em que as transações ocorrem, os indivíduos possuem informações difusas e incompletas sobre seus próprios interesses. Isso significa que qualquer agente econômico pode estar sujeito a agir ou sofrer uma ação oportunista, pois fatos supervenientes podem estimular a quebra dos contratos estabelecidos.

\subsection{Cadeias produtivas, contratos e oportunismo}

Morvan (1985) define uma cadeia produtiva (filière) como uma sequência de operações que levam à produção de bens, cuja articulação é influenciada pela fronteira de possibilidades ditadas pela tecnologia e é definida pelas estratégias dos agentes (elos da cadeia) que buscam a maximização dos seus resultados. Uma importante construção no sentido da ampliação do conceito e da forma de se trabalhar em termos de cadeias produtivas é o conceito de Sistema Agroalimentar (SAG), que envolve outros elementos, tais como o ambiente institucional e organizacional no qual se inserem as cadeias produtivas (FARINA; AZEVEDO; SAES, 1997). O sistema é considerado um "conjunto de relações contratuais entre empresas e agentes especializados, cujo objetivo final é disputar o consumidor final de determinado produto" (ZYLBERSZTAJN, 2000, p. 13). Assim, é possível entender que, entre cada agente (elo) de uma cadeia produtiva ou SAG, forma-se um mercado $(T 1, T 2, \ldots, T n)$ que pode ser regido por diferentes tipos de transações, que podem ser desde transações tópicas de mercado até uma forma contratual mais rígida, representada pela integração.

Em se tratando de relações entre dois elos de uma cadeia produtiva, a confecção dos contratos deveria ter como critério a maximização conjunta do lucro. No entanto, muitas vezes os agentes se comportam de forma oportunista, destruindo a confiança, elemento básico de uma relação contratual que dispensaria a formalização e reduziria os custos de transação. A necessidade de confiança entre os agentes em uma transação e o comprometimento de ambas as partes são imprescindíveis para ocorrer uma transação. A confiança atuaria sobre parcerias, "permitindo que estas ocorram sobre as bases que dispensam ou diminuem a necessidade de mecanismos de controle e execução dos contratos" (BEGNIS; ESTIVALETE; PEDROZO, 2007, p. 315).

Caso uma transação venha a apresentar algum grau de risco ou incerteza para um dos agentes, este teria a percepção de que as informações sobre seu parceiro ou sobre a transação seriam incompletas. Disso resulta a necessidade de algum grau de confiança para que a transação possa ser concluída. Por outro lado, o risco de confiar estaria relacionado à perspectiva de retorno que obteria o agente que estivesse confiando. Caso a perspectiva de retornos não estivesse clara, este agente não viria a investir na confiança. Neste caso, a confiança significa a conviç̧ão de que o parceiro executaria ações que viessem a trazer um resultado positivo para ambos os agentes.

\subsection{Características das transações e oportunismo}

Williamson (1985) considera três dimensões para as transações: frequência, incerteza e especificidade dos ativos. A frequência refere-se ao número de vezes em que uma transação se efetiva. A frequência das transações poderia influenciar os custos associados a uma transação pela possibilidade de construção de reputação por parte dos agentes envolvidos na transação. 
Quanto maior a frequência da transação, maior a motivação dos agentes de não imporem perdas para seus parceiros, porque a quebra de contratos causaria perdas de rendas futuras. O desenvolvimento da reputação limita o interesse dos agentes em agir de forma oportunista para obter ganhos de curto prazo. Quanto maior a frequência com que ocorrem as transações, menores serão os custos advindos da coleta de informação para a efetivação dos contratos e de cláusulas contratuais complexas que limitem o comportamento oportunista.

Outra dimensão é a incerteza, entendida como a impossibilidade de previsão de choques ou mudanças que viessem a alterar as características dos resultados da transação (Williamson, 1985; Farina; AVEVEDO; SAES, 1997; Zylbersztajn, 2000; Feltre; Paulillo, 2006). Disso resulta que os agentes, limitados para preverem os acontecimentos futuros, não seriam capazes de desenhar cláusulas contratuais capazes de associar a distribuição dos resultados aos impactos externos. Com isso, estariam sujeitos a um aumento das lacunas que um contrato não poderia cobrir, culminando em oportunidades para ocorrência de comportamento oportunista.

A terceira dimensão é a especificidade dos ativos. Segundo Williamson (1985), especificidade dos ativos faz referência ao grau em que um ativo poderia ser reempregado para um uso alternativo sem perder valor produtivo. Assim, um ativo específico seria aquele que não poderia ser reempregado para outra atividade sem perder valor. Quanto maior a especificidade dos ativos, maior seria o risco e a necessidade, por parte dos agentes, de se precaverem quanto à não efetivação da transação, pois não encontrariam um uso alternativo que mantivesse o valor do ativo.

Com base nas características das transações, Williamson (1985) apresenta um modelo para escolha da forma organizacional mais adequada, considerando que a especificidade dos ativos influencia de forma determinante a eficiência das formas de governança. $\mathrm{O}$ argumento de Williamson (1985) é montado tendo como referência a comparação de três estruturas de governança: o mercado, a hierarquia e uma forma híbrida. O mercado e a forma hierárquica de governança seriam considerados formas opostas, tendo como diferença a influência causada por incentivo e controle sobre a forma de governança. Williamson (1985) também apresenta a comparação entre mercado e hierarquia, em três níveis que se completam. Primeiro, dando ênfase a aspectos tecnológicos, no que afirma que o mercado seria mais eficiente por conseguir se aproveitar melhor das economias de escala e escopo. Argumenta que esse processo ocorreria em função de as empresas visarem um mercado consumidor maior que o mercado interno à forma de organização (governança) hierárquica. Um segundo elemento de comparação seria a estrutura de informação, pois no mercado as informações seriam privadas e adquiridas de forma descentralizada, o que possibilitaria a utilização da informação de forma imediata. Já na forma hierárquica, as informações seriam comuns aos agentes e adquiridas de forma central, o que, segundo Hayek (1945), dificultaria a pronta utilização do conhecimento de circunstâncias particulares de tempo e espaço. O terceiro elemento de comparação seria organizacional. Williamson (1985) parte do princípio de que as transações são a unidade de análise e considera que as transações que ocorrem internamente na forma hierárquica seriam diferentes das transações de mercado. Para fazer a diferenciação entre mercado e hierarquia, o autor analisa como se dá a existência de incentivos e controles nas transações que ocorrem sob essas formas.

Williamson (1985) afirma que, na forma hierárquica, poderia ocorrer pouco incentivo às mudanças nas ações desejadas (transações), em função de que mudanças no esforço despendido teriam pouco ou nenhum efeito imediato sobre a remuneração. Porém esses incentivos fracos seriam responsáveis por promover um comportamento cooperativo. Os efeitos negativos da falta de incentivos fortes seriam amenizados pela existência de controles internos na forma hierárquica. Os mecanismos de controle são vistos como meios de garantir determinado comportamento dos agentes na ausência da confiança (Das; Teng, 1998). 


\subsection{A confiança como base das relações contratuais}

Para Hill (1990), os teóricos dos custos de transação geralmente negligenciam os mecanismos automáticos de ajustamento dos mercados ao considerar o risco de comportamentos oportunistas. Porém, argumenta que os oportunistas prosperam frente à falha do mecanismo de seleção dos mercados, mas quando esses mecanismos falham, entram em cena as instituições e organizações, que desempenham o papel de eliminação dos agentes oportunistas. Como as transações estão inseridas num contexto econômico mais amplo, são os comportamentos cooperativos que se sobrepõem ao oportunismo.

Algumas estruturas de mercado e o próprio ambiente no qual as transações ocorrem se mostram mais propensos à fraude, a comportamentos imprevisíveis e à fraca estabilidade. Parkhe (1993) destaca que a potencial conduta oportunista afeta tanto a estrutura dos relacionamentos como sua performance. Assim, os parceiros se veem forçados a erigir estruturas de governança e controle que influenciam negativamente o objetivo da parceria. Os riscos que podem ocorrer nas relações entre os parceiros requerem dos agentes diferentes percepções: a confiança entre as partes e o controle são variáveis presentes em todas as transações (MARCONATTO; ESTIVALETE; PEDROZO, 2015). A capacidade de administrar e/ou reduzir os riscos gera vantagens competitivas entre as organizações (LIVATO; BENEDICTO, 2010).

A escolha da forma de governança depende da confiança entre os parceiros e seus repetitivos vínculos (GULATI, 1995). Nooteboom, Berger e Noorderhaven (1997) concluem que, enquanto cresce a confiança, a necessidade de estruturas complexas de governança diminui, assim como os custos de transação. Na mesma direção, Dyer $(1996,1997)$ concluiu que existe relação positiva entre a especificidade dos ativos da cadeia de valor criada pela rede de relacionamentos e o desempenho global dos parceiros envolvidos. Segundo ele, os fatores que influenciam a geração de vantagem competitiva por uma estratégia de rede estão relacionados ao ambiente institucional (custos de contrato, confiança), à incerteza e volatilidade da indústria (choques externos) e à interdependência do produto/tarefa.

Confiança é igualmente o elemento-chave para Hagen e Choe (1998), que a apresentam como a força condutora das relações de parcerias. Destaca-se, então, que o sucesso das parcerias exige um alto nível de confiança na cooperação dos parceiros. Das e Teng (1998) definem confiança na cooperação dos parceiros como a "certeza percebida pela firma sobre a cooperação satisfatória do parceiro" (p. 492). Neste sentido, a cooperação é caracterizada pela honestidade e pelo comprometimento ou, em outras palavras, pelo "jogo limpo". No ambiente organizacional, na complexidade das variáveis internas e internas que interferem nas rotinas, a confiança é representada pelas expectativas positivas que podem ser geradas entre as relações dos agentes (PIRANI; CUNHA, 2010).

Kale, Singh e Perlmutter (2000) observam que o capital relacional, alicerçado na confiança mútua e na interação ao nível individual entre os parceiros de uma aliança, cria a base para o aprendizado e para a transferência de know-how através de interfaces de trocas. Ao mesmo tempo, o capital relacional barra o comportamento oportunista dos parceiros da aliança e previne o vazamento de conhecimentos críticos. Em síntese, pode-se afirmar que a confiança e o oportunismo nas parcerias de negócio podem não ser considerados mecanismos opostos, mas coexistentes. A confiança permite que as parcerias se estabeleçam sobre bases que dispensam ou diminuem a necessidade de mecanismos de controle e execução dos contratos. Portanto, é um forte artifício para a superação de custos de transação e contribui para o sucesso das parcerias. 
O Quadro 1 apresenta os principais conceitos utilizados na elaboração do instrumento de pesquisa, juntamente com as referências teóricas que serviram de base para sua construção. Como já apresentado na fundamentação teórica, as maiores contribuições foram de Williamson $(1985,1998)$, Simon (1956, 1997, 2000), Das e Teng (1998), Dyer (1996, 1997), Hill (1990) e Hagen e Choe (1998).

Quadro 1 - Base conceitual do instrumento de pesquisa

\begin{tabular}{|c|c|}
\hline Conceito teórico/Variável de análise & Referência \\
\hline Reputação & Williamson (1985); Das e Teng (1998) \\
\hline Racionalidade limitada & Simon (1997, 2000) \\
\hline Dependência bilateral & Williamson (1998) \\
\hline Frequência das transações & Williamson (1985) \\
\hline Oportunismo & Dyer (1985) \\
\hline Incerteza e volatilidade da indústria 1997$)$ \\
\hline Mecanismo de ajustamento automático de mercado & Hill (1990) \\
\hline Confiança & Das e Teng (1998); Hagen e Choe (1998) \\
\hline Influência do ambiente na escolha racional & Simon (1956) \\
\hline
\end{tabular}

Fonte: elaborado pelos autores.

\section{PROCEDIMENTOS METODOLÓGICOS}

A pesquisa realizada teve caráter descritivo-explicativo, e foi realizado um levantamento de dados (survey) através da interrogação dos participantes, dos quais se procurou obter informações sobre seu comportamento, intenções, atitudes, percepção, motivações e características demográficas e de estilo de vida. A delimitação do estudo foi relativa à safra de 2007/2008, abrangendo os produtores de tabaco dos três estados do Sul do Brasil: Rio Grande do Sul, Santa Catarina e Paraná. Segundo o Anuário Brasileiro do Fumo (2007), a safra de 2007/2008 contou com 182 mil produtores integrados, distribuídos em 780 municípios, resultando uma área plantada total de 344 mil hectares e uma produtividade média de 2.044 quilos de tabaco por hectare. Desta população, foram escolhidos 1.437 produtores por conveniência, que não apresentaram incidência de granizo ou vendaval (fatores que, caracterizando-se como um evento externo, poderiam influenciar de forma negativa as respostas dos entrevistados). A distribuição dos entrevistados por estado foi de 629 produtores no Rio Grande do Sul, 498 em Santa Catarina e 310 no Paraná. A reconhecida homogeneidade da população em relação às suas características socioeconômicas torna essa amostra representativa, dado que, para a mesma população e nível de confiança de 95\%, Arend (2014) trabalhou com uma amostra de 1.200 fumicultores para os três estados.

O levantamento dos dados foi realizado através de entrevista pessoal na residência do entrevistado, tendo como instrumento um questionário com respostas fechadas, aplicado de forma a garantir o anonimato do respondente. Para viabilizar a pesquisa, os questionários foram aplicados por entrevistadores da Afubra no momento da realização da pesquisa anual de safra realizada por essa entidade. Além da vantagem de redução significativa do custo da pesquisa, existe a facilidade proveniente da imagem da Afubra frente aos agricultores e da experiência dos entrevistadores na coleta de dados. $\mathrm{O}$ entrevistador fez a leitura das questões sempre obedecendo à mesma ordem, e a coleta de cada resposta foi feita sempre após cada pergunta. Os dados coletados foram tabulados em planilhas eletrônicas, para a posterior análise de consistência e das relações estabelecidas entre as variáveis. $O$ tratamento estatístico dos dados foi desenvolvido com o emprego do software SPSS (Statistical Package for the Social Sciences), utilizando-se recursos para a geração das estatísticas descritivas, análise de correlação, análise fatorial e análise de clusters. 
Uma vez que a questão central da pesquisa envolve a diferença nas características entre produtores que quebraram seus contratos com a empresa integradora, foi empregado como critério para a distinção entre a quebra contratual ou não a resposta à questão 18 do referido questionário, que indagava se, na safra $2007 / 2008$, o entrevistado tinha vendido o fumo produzido para outra firma que não a contratante. Desse modo, considerou-se que houve quebra contratual quando o entrevistado respondeu que efetuou a venda de parte ou de toda a produção de tabaco para firma diversa daquela com a qual havia contratado a produção.

Para a diferenciação entre os produtores que desviaram a produção (parcial ou totalmente, quebrando o contrato firmado) e os que não desviaram, foi utilizado o teste de hipótese para diferença de médias entre grupos com base na estatística t. O mesmo procedimento foi utilizado para a verificação de diferenças de comportamento e características dos produtores entre os três estados pesquisados.

Complementando a análise, foi utilizada a análise de cluster para a criação de dois grupos distintos de produtores, os que não cumpriram o contrato integralmente e os que o cumpriram. O propósito da análise de cluster é buscar uma classificação de acordo com as relações naturais que a amostra apresenta, formando grupos de objetos por similaridade. Os grupos são formados de acordo com a semelhança em relação a algum critério pré-determinado. Normalmente, a análise de clusters é precedida da análise fatorial, a qual agrupa variáveis formando um fator que pode servir de elemento classificador no processo de formação de grupos. Segundo Hair et al. (2005), os agrupamentos (ou clusters) resultantes apresentam uma elevada homogeneidade interna (dentro dos grupos) e uma elevada heterogeneidade externa (entre os grupos). Portanto, a análise de cluster permite identificar o perfil de cada grupo, o qual é definido pelas características que compõem o cluster, baseando-se no conceito de similaridade.

Para isso, os dois clusters (os produtores que quebraram o contrato e os que não quebraram) foram estabelecidos a partir do fator obtido da análise fatorial, que está relacionado à quebra contratual por parte dos produtores. Como resultado, obteve-se a formação de dois grupos homogêneos, sendo o primeiro (Cluster 1) composto por 727 produtores com menor incidência de quebra contratual e o segundo (Cluster 2) composto por 710 produtores com maior incidência de quebra contratual na safra de referência da pesquisa.

\section{PERFIL DOS PRODUTORES E COMPORTAMENTO OPORTUNISTA}

Partindo dos dados obtidos pela pesquisa, foi possível determinar as principais características sociais e econômicas dos produtores de tabaco do Sul do Brasil, assim como suas percepções e comportamentos dentro de suas relações com as empresas.

\subsection{Características socioeconômicas}

Tratando das condições sociais e econômicas dos produtores de tabaco dos três estados pesquisados, podem ser salientados alguns destaques apontados pela pesquisa. Quanto ao grau de instrução, este se revelou bastante baixo: quase $70 \%$ dos produtores possuem apenas o Ensino Fundamental incompleto. Os produtores paranaenses são os que apresentam maior escolaridade: $22 \%$ destes possuem um grau de instrução acima do Ensino Fundamental completo. Em oposição, os produtores gaúchos são os que apresentam o menor índice de escolaridade: $82 \%$ têm o Ensino Fundamental incompleto. 
As propriedades rurais produtoras de tabaco pesquisadas apresentam um tamanho médio de 15,2 hectares, e as lavouras de tabaco ocupam em média 2,8 hectares. O Paraná possui o menor número de produtores de tabaco, como também o tamanho médio das unidades produtoras é um pouco menor do que a média da região, 12,9 hectares. A maior parte (43\%) das propriedades rurais produtoras de tabaco na Região Sul possui área de até 10 hectares, sendo que as propriedades com área acima de 30 hectares somam apenas $9 \%$. Em relação à condição de posse da área cultivada, $78 \%$ são proprietários das terras da lavoura. Em Santa Catarina, esse percentual é maior, de $87 \%$. O cultivo de tabaco em terras arrendadas é mais observado no Paraná. Nos três estados, os produtores, em média, desenvolvem essa atividade por mais de 17 anos, sendo que apenas 30\% têm uma experiência inferior a dez anos no cultivo, destacando-se que $33 \%$ estão há mais de vinte anos na atividade. Isso revela que grande parte dos produtores pode ser considerada experiente no cultivo do tabaco.

Das unidades de produção pesquisadas, $84 \%$ não apresentam outra fonte significativa de renda que não seja da atividade agrícola. Esse dado é reforçado pela verificação de que em $48 \%$ das unidades de produção não existe outra fonte de renda agrícola de importante significado econômico. No Rio Grande do Sul, apenas $40 \%$ dos entrevistados manifestaram possuir outra atividade agrícola, que não o cultivo do tabaco, relevante para a formação da renda familiar. Há, portanto, uma forte dependência dos produtores em relação à renda derivada da produção de tabaco. A pesquisa reforçou que a atividade produtiva do tabaco é executada principalmente com o emprego de mão de obra familiar. Em $51 \%$ dos casos, tem-se a participação do proprietário e de sua esposa nas lides do tabaco e, em $37 \%$, o envolvimento de todos da família. Quando há a contratação de mão de obra externa ao núcleo familiar do produtor, esta se dá principalmente no período da colheita.

\subsection{Relações entre produtor e indústria}

A produção de tabaco normalmente ocorre dentro de um sistema de integração no qual a firma integradora compromete-se, contratualmente, a comprar a produção do agricultor, que, em contrapartida, assume a obrigação de produzir o tabaco na quantidade determinada pelo contrato e segundo as especificações técnicas da firma compradora. Quanto à percepção dos produtores sobre o SIP, a pesquisa revelou que $77 \%$ destes acreditam que o sistema gera benefícios tanto para os produtores quanto para a indústria. $O$ contrato de integração configura-se em uma obrigação de produzir. Nesse sentido, a prática de produzir além do contratado é comum entre os produtores, pois $35 \%$ destes revelaram que assim procedem. No Paraná, isso é ainda mais comum, pois $58 \%$ dos produtores revelaram produzir mais do que a quantidade firmada em contrato.

Do ponto de vista teórico, o tempo de relacionamento entre agentes em um mercado é um determinante para a formação da reputação. Os produtores entrevistados apresentavam, em média, um relacionamento de dez anos com a firma contratante, e $42 \%$ dos produtores apresentavam um relacionamento de mais de dez anos com essa firma. Além disso, $39 \%$ dos produtores revelaram ter, durante todo o tempo em que se dedicaram à produção de tabaco, mantido contrato com apenas uma empresa. De modo geral, há uma percepção de que nesse mercado vem crescendo a ocorrência de quebras contratuais por parte dos produtores rurais. A pesquisa identificou que $36 \%$ dos entrevistados já haviam vendido tabaco para outras empresas que não aquela que contratou a produção. Essa parcela é menor entre os produtores do Paraná, alcançando $24 \%$ dos entrevistados. Durante a safra tomada como referência para a pesquisa, $57 \%$ dos produtores entrevistados afirmaram ter recebido várias propostas de compra de sua produção por agentes 
individuais ou representantes de empresas diferentes. Os produtores mais assediados por esses agentes são os de Santa Catarina, onde $80 \%$ revelaram ter recebido duas ou mais propostas de compra da produção. A pesquisa também revelou que $50 \%$ das propostas de compra por parte de um atravessador apresentam preço superior ao que foi contratado com a firma integradora.

Ainda em termos de preços, $60 \%$ dos entrevistados declararam que se consideram satisfeitos com os preços pagos pela firma contratante da safra. Apesar desse contentamento, $33 \%$ dos produtores revelaram ter quebrado o contrato com a firma integradora, vendendo parte ou toda produção contratada na safra de referência da pesquisa. Sobre esta prática, $60 \%$ dos produtores pesquisados consideram que é algo errado, mas que se justifica, e $8 \%$ pensam que é uma prática normal e vantajosa. Apesar disso, os produtores confiam que a empresa contratante da safra esteja preocupada que ele faça uma boa safra e que o tabaco colhido lhe dê um bom lucro. Apenas $6 \%$ pensam que a indústria não tem essa preocupação para com os produtores. Sobre a fidelidade com a firma contratante da safra, $86 \%$ dos produtores entendem que esta traz benefícios para as duas partes envolvidas na transação, ou seja, produtor e indústria.

O contrato estabelecido entre o produtor e a empresa é uma peça jurídica de caráter formal, estabelecendo compromissos e direitos entre as partes. No entanto, apenas $55 \%$ dos produtores pesquisados consideram que o contrato firmado representa um compromisso que deve ser totalmente atendido, sendo que $5 \%$ avaliam que o contrato é apenas uma mera formalidade, sem qualquer efeito, e $40 \%$ entendem que o contrato representa apenas uma intenção de compra e venda. Apesar disso, $75 \%$ dos entrevistados apontam que, para o rompimento do contrato com a empresa, a diferença entre o preço acordado e o preço oferecido pelo agente atravessador deveria ser muito grande. De outro lado, apenas $18 \%$ dos produtores afirmam que não romperiam o contrato, independentemente da oferta que lhe tenha sido feita por atravessadores ou outras firmas. Esse percentual é maior entre os produtores paranaenses, alcançando $32 \%$ dos pesquisados e indicando uma maior propensão à fidelidade desses produtores.

Nas transações, outro elemento importante é a informação das partes sobre o objeto da transação. Quanto a esse aspecto, $95 \%$ dos entrevistados manifestaram possuir pouco ou nenhum conhecimento sobre o mercado internacional do tabaco, balizador dos preços para o mercado interno, afetando diretamente os ganhos dos produtores. A totalidade dos produtores pesquisados possui algum tipo de dívida. As mais citadas pelos produtores são com o Programa Nacional de Fortalecimento da Agricultura Familiar (Pronaf), mencionado por $46 \%$ dos entrevistados, e com as empresas integradoras, citadas por $41 \%$ dos respondentes. Cabe destacar que é bastante comum o endividamento com mais de uma fonte de crédito.

Por fim, cerca de $90 \%$ dos produtores entrevistados entendem que seus investimentos específicos para a cultura do tabaco já foram recuperados. Entre esses ativos específicos, citamse como principais as estufas de secagem e cura do tabaco, pelo seu peso frente aos investimentos necessários à produção e pela sua estrita especificidade de uso. Apesar das atuais incertezas presentes no mercado trazidas pela Convenção-Quadro para o Controle do Tabaco, das negociações para a formação dos preços, entre outras questões, $74 \%$ dos produtores revelaram não ter intenção de abandonar o cultivo do tabaco. Os produtores catarinenses se mostraram menos satisfeitos, pois entre estes $37 \%$ têm intenção de parar de cultivar o tabaco.

\subsection{Diferenças regionais}

Empregando testes de hipóteses para as diferenças das médias entre grupos dentro da amostra com base na Estatística $t$, foi possível estabelecer em que características e compor- 
tamentos os produtores de tabaco do Rio Grande do Sul, Santa Catarina e Paraná diferem. Percebe-se que há diferenças entre os produtores dos três estados na maior parte das questões. No entanto, algumas percepções são comuns entre os produtores de tabaco do Sul do Brasil. A similaridade entre as respostas localiza-se principalmente em temas que afetam diretamente a produção e o sistema integrado.

Não é possível afirmar que exista diferença significativa de respostas em questões como a renda proveniente de atividade não agrícola, a contratação de mão de obra externa complementar, o tamanho da lavoura de tabaco, a percepção sobre as vantagens do SIP, o preço oferecido pelo agente atravessador para a compra da safra contratada por outra firma, o nível de satisfação com os preços pagos pela firma contratante da safra e as percepções sobre os benefícios da fidelidade. Por outro lado, é possível ressaltar que existe maior identidade entre os produtores gaúchos e catarinenses, ao passo que as respostas dos produtores do Paraná divergem das respostas dos produtores do Rio Grande do Sul e Santa Catarina em $67 \%$ das questões. Com isso, pode-se concluir que, sendo a produção de tabaco no Paraná uma atividade mais recente que nos outros dois estados, o perfil dos produtores é diferente.

\subsection{Características dos produtores que apresentaram quebra contratual}

Entre os produtores pesquisados, um em cada três praticou a quebra contratual, vendendo parcial ou integralmente sua produção para outro agente ou empresa, destacando-se que no Paraná há menor incidência de quebra contratual ( $25 \%$ dos produtores), enquanto no Rio Grande do Sul e em Santa Catarina 35\% dos entrevistados assumiram ter rompido total ou parcialmente o contrato estabelecido. Entre os produtores que apresentaram quebra contratual, 0 grau de instrução é bastante baixo, sendo que $70 \%$ destes não têm instrução ou possuem apenas o Ensino Fundamental incompleto, o que não difere do conjunto dos produtores pesquisados.

O tamanho médio das propriedades deste grupo também não é muito diferente, 14,6 hectares, assim como o tamanho das lavouras de tabaco que ocupam, que é, em média, de 2,9 hectares. Igualmente, a maior parte (45\%) das propriedades rurais nas quais se verificou a quebra contratual tem até 10 hectares. Também não há diferença em relação à condição de posse da área cultivada, pois $76 \%$ dos produtores deste grupo são proprietários das terras da lavoura. Quanto ao tempo de dedicação à atividade do cultivo do tabaco, este grupo apresenta características semelhantes ao conjunto da amostra. Os produtores, em média, já desenvolvem essa atividade por mais de 17 anos, e $36 \%$ já estão há mais de vinte anos na atividade. Nas unidades de produção onde ocorreu a quebra contratual, $86 \%$ não apresentam outra fonte significativa de renda que não seja da atividade agrícola e em $51 \%$ destas unidades não existe outra fonte de renda agrícola de importante significado econômico. Novamente, estas duas últimas características não apresentam significativa diferença frente ao conjunto dos produtores, da mesma forma que em relação ao emprego de mão de obra familiar. Em $48 \%$ dos casos em que houve a quebra contratual, observa-se a participação do proprietário e de sua esposa nas lides do tabaco e em $39 \%$ o envolvimento de todos da família.

Em relação à contratação de mão de obra externa ao núcleo familiar, surge uma diferença significativa entre aqueles que manifestaram ter rompido o contrato com a empresa integradora e os demais produtores que não adotaram essa prática. A contratação de mão de obra externa é mais frequente ( $71 \%$ dos casos) entre os produtores que romperam o contrato com a empresa, enquanto no grupo em que não houve a quebra de contrato a parcela de produtores que contrata mão de obra externa é de $63 \%$. 


\subsection{Relações entre produtor e indústria na presença da quebra contratual}

Os produtores que apresentaram quebra contratual possuem, em média, um relacionamento de nove anos com a firma que havia contratado a safra. Destaca-se que $42 \%$ desses produtores apresentam um relacionamento de menos de cinco anos com a firma, ao passo que, nessa mesma faixa, os produtores que não quebraram contratos somam apenas $35 \%$. Sobre o tempo de relacionamento com as firmas, os produtores que romperam contratos possuem um tempo de relacionamento menor com a empresa, diferente do que ocorre no grupo de produtores quem não quebraram o contrato na safra pesquisada, os quais apresentam relacionamentos mais duradouros.

Entre os produtores que efetuaram a quebra contratual, $61 \%$ revelaram ter mantido contrato, durante todo o tempo em que se dedicaram à produção de tabaco, com apenas uma ou duas empresas, enquanto no grupo em que não houve a quebra contratual esse percentual passou para $75 \%$. Quanto à percepção dos produtores sobre o SIP, 31\% dos produtores que romperam o contrato consideram que esse sistema produz benefícios apenas para a indústria. De outro lado, somente $18 \%$ dos produtores que não romperam seu compromisso com a empresa integradora acreditam que os benefícios do sistema sejam exclusivamente da indústria.

A prática de produzir além do contratado também é uma característica comum: $33 \%$ dos produtores que romperam contratos assim o fizeram, e $36 \%$ dos que não romperam também produziram além do contratado. $O$ histórico de quebras contratuais é um elemento comum entre os produtores que romperam o contrato na safra de referência da pesquisa: $63 \%$ destes afirmaram já ter agido dessa forma em safras anteriores. Entre os produtores que não romperam o contrato, apenas $22 \%$ revelaram ter se utilizado desse expediente em tempos passados. Na safra referência (2007/2008), cerca de $80 \%$ dos produtores que romperam o contrato afirmaram ter recebido duas ou mais propostas de compra de sua produção por atravessadores ou outras empresas. Na maior parte das vezes (76\%), essas propostas correspondiam a um preço superior àquele praticado pela firma integradora.

Entre os produtores que não quebraram seu contrato, o percentual daqueles que receberam duas ou mais propostas de compra cai para $61 \%$, sendo que somente em $40 \%$ dos casos o preço oferecido foi maior do que o acordado com a firma que contratou a produção. Novamente cabe o destaque aos produtores de Santa Catarina, pois, entre os que romperam o contrato, $94 \%$ haviam recebido duas ou mais propostas de compra da produção. No grupo de entrevistados que revelou ter quebrado o contrato, $64 \%$ declararam estar insatisfeitos ou muito insatisfeitos com os preços pagos pela firma contratante da safra. Essa parcela é de apenas $30 \%$ entre os produtores que honraram o compromisso contratual na safra estudada. Entre aqueles produtores que quebraram a relação contratual, $87 \%$ o fizeram vendendo parcialmente a produção contratada para outra firma ou agente e $13 \%$ vendendo toda a sua produção. Oitenta por cento destes produtores consideram que essa é uma prática errada, mas que se justifica; $12 \%$ acreditam que é uma prática normal e vantajosa, e somente $8 \%$ revelam ter ciência de que tal atitude é desonesta. Em contraponto, $43 \%$ dos produtores que não quebraram o contrato na safra de referência da pesquisa consideram a venda do tabaco contratado como algo desonesto.

De modo geral, os produtores acreditam que a empresa integradora esteja engajada, no sentido de que espera que eles façam uma boa safra e de que o tabaco colhido lhes dê um bom resultado econômico. Apenas $10 \%$ daqueles que quebraram o contrato na safra pesquisada pensam que a indústria não tem essa preocupação, ao passo que $5 \%$ dos que não quebraram o contrato tem essa mesma percepção negativa em relação à firma integradora. Para aqueles que quebraram o contrato, $19 \%$ entendem que a fidelidade com a firma contratante da safra traz benefícios unicamente para esta, enquanto esse percentual cai para $11 \%$ entre os que não efetuaram a quebra contratual. 
O contrato estabelecido entre o produtor e a empresa é visto por apenas $35 \%$ dos produtores que exerceram a quebra contratual como um compromisso que deve ser totalmente atendido e por outros $59 \%$ como uma intenção de compra e venda que pode ser modificada ou parcialmente cumprida. Em contraponto, para $65 \%$ dos produtores que não exerceram a quebra contratual, o contrato estabelecido é um compromisso que deve ser integralmente cumprido. No grupo de produtores em que houve quebra contratual, $85 \%$ apontam que, para o rompimento do contrato com a empresa, a diferença entre o preço acordado e o preço oferecido pelo agente atravessador deveria ser muito grande. Já entre os produtores que não romperam o contrato, independentemente da oferta que lhes seja oferecida por atravessadores ou outras firmas, $25 \%$ afirmam que não quebrariam o contrato com a firma.

Quanto ao nível de informação que cada parte possui sobre o mercado internacional do tabaco, pode-se concluir que não há diferença entre os produtores, pois todos manifestaram ter pouco ou nenhum conhecimento sobre o principal mercado do produto. Assim como a totalidade dos produtores pesquisados apresenta algum grau de endividamento, isso também se verifica entre os produtores que romperam o contrato na safra observada. Porém, estes produtores diferem daqueles que não romperam o contrato quando se observam suas dívidas com fornecedores de insumos e comerciantes locais, sendo que esse tipo de crédito é mais frequente entre os produtores que romperam o contrato.

Em relação aos investimentos específicos para a cultura, entre os produtores que praticaram a quebra contratual, $14 \%$ revelaram ainda não recuperar seu capital. Já entre os produtores que não quebraram o contrato, esse percentual é menor (10\%). Por fim, da mesma forma que os demais produtores, aqueles que exerceram a quebra contratual na safra pesquisada não têm a intenção de parar com o cultivo do tabaco.

\subsection{Diferenças entre os grupos de produtores}

Novamente utilizando-se de testes de hipóteses para as diferenças das médias entre o grupo que exerceu a quebra contratual na safra de referência $(2007 / 2008)$ e o grupo que não efetuou a quebra, com base na Estatística t foi possível estabelecer em que características e comportamentos esses dois grupos de produtores diferem. A partir das questões relacionadas no Quadro 2, é possível afirmar que existem significativas diferenças entre produtores que quebraram o contrato com a empresa integradora e aqueles que não o fizeram. As diferenças nas médias das respostas são estatisticamente significantes em mais da metade das questões consideradas.

Quadro 2 - Questões em que há diferenças entre os produtores que romperam contratos e os que não romperam

\begin{tabular}{|c|}
\hline Questão \\
\hline 08 - Contratação de mão de obra externa \\
\hline 09 - Tempo de relacionamento com a firma que contratou a atual safra \\
\hline 10 - Número de firmas com as quais os produtores já mantiveram contratos \\
\hline 12 - Percepção sobre as vantagens do SIP \\
\hline 14 - Quebra contratual na safra anterior \\
\hline 15 - Proposta de compra da produção por outro agente \\
\hline 16 - Preço oferecido pelo agente para a compra da safra contratada por outra firma \\
\hline 17 - Nível de satisfação com os preços pagos pela firma contratante da safra \\
\hline 20 - Percepção sobre o interesse da firma contratante para com o bom desempenho econômico do \\
produtor
\end{tabular}




\begin{tabular}{|c|}
\hline 21 - Percepção sobre os benefícios da fidelidade \\
\hline $22-$ Entendimento do produtor quanto ao compromisso contratual \\
\hline $24-$ Estímulos necessários para o rompimento do contrato \\
\hline 25 - Endividamento do produtor: com Fornecedores de Insumos e com Comércio Local \\
\hline 26 - Recuperação do investimento nos ativos especializados \\
\hline
\end{tabular}

Fonte: dados da pesquisa.

Em síntese, os dois grupos de produtores apresentam características socioeconômicas semelhantes e diferem principalmente nas questões que envolvem o relacionamento com a indústria.

\subsection{Análise de cluster}

O estudo utilizou a análise de cluster com o objetivo de estabelecer dois grupos distintos de produtores de tabaco: os que quebram contratos e aqueles que não adotam essa prática. Como resultado, obteve-se a formação de dois grupos homogêneos, sendo o primeiro (Cluster 1) composto por 727 produtores com menor incidência de quebra contratual e o segundo (Cluster 2) composto por 710 produtores com maior incidência de quebra contratual na safra de referência da pesquisa. No Cluster 1, 37\% dos produtores são do Rio Grande do Sul, 35\% de Santa Catarina e $28 \%$ do Paraná. Quanto ao grau de instrução, neste cluster, $66 \%$ dos produtores possuem apenas o Ensino Fundamental incompleto. As propriedades rurais que compõem este grupo apresentam um tamanho médio de 15,8 hectares, e as lavouras de tabaco ocupam, em média, 2,7 hectares. Verificou-se que a maior parte (43\%) das propriedades possui área de até 10 hectares, sendo que as propriedades com área acima de 30 hectares somam $11 \%$. Quanto ao tamanho das lavouras de tabaco, 31\% destas possuem área superior a 3 hectes. Em relação à condição de posse da área cultivada, $78 \%$ são proprietários das terras da lavoura. Em Santa Catarina, esse percentual é maior (88\%), sendo que o cultivo de tabaco em terras arrendadas é maior no Paraná, onde somente $66 \%$ são proprietários das terras cultivadas.

Os produtores do Cluster 1 , em média, já desenvolvem essa atividade por 16 anos, sendo que $33 \%$ têm uma experiência inferior a dez anos no cultivo do tabaco, enquanto $29 \%$ já estão há mais de vinte anos na atividade. Em $82 \%$ das unidades de produção deste cluster, não se verifica outra fonte significativa de renda que não seja da atividade agrícola e cabe destacar que em $54 \%$ das unidades de produção não existe outra fonte de renda agrícola de importante significado econômico que não esteja vinculada à produção do tabaco. Já no Rio Grande do Sul, apenas $39 \%$ dos componentes deste grupo manifestaram possuir outra atividade agrícola, relevante para a formação da renda familiar. A dependência dos produtores em relação à renda derivada da produção de tabaco é mais evidente no estado gaúcho.

A atividade produtiva do tabaco é executada, em $53 \%$ dos casos do Cluster 1 , pelo proprietário e sua esposa e em $35 \%$ há o envolvimento de todos da família. A contratação de mão de obra externa ao núcleo familiar do produtor ocorre principalmente no período da colheita (30\% dos casos), porém cabe destacar que, neste grupo, em $40 \%$ das unidades de produção, não há contratação de mão de obra externa.

Os produtores do Cluster 1 , em média, possuem um relacionamento de dez anos com a firma que havia contratado a safra de referência para a pesquisa; $34 \%$ dos produtores apresentam um relacionamento de até cinco anos com essa firma; e 50\% dos produtores revelaram ter mantido, durante todo o tempo em que se dedicaram à produção de tabaco, contrato com apenas uma empresa. Quanto à percepção sobre o SIP, $90 \%$ dos produtores acreditam que o sistema gera benefícios para todos os envolvidos (produtores e indústria). Produzir tabaco além do que 
foi contratado com a firma integradora é uma prática pouco comum entre os produtores desse grupo, uma vez que $67 \%$ revelaram plantar exatamente a área que foi contratada com a indústria.

No Cluster 1 , apenas $11 \%$ dos produtores já haviam vendido tabaco para outras empresas que não aquela que contratou a produção. Essa parcela é maior entre os produtores de Santa Catarina, alcançando $16 \%$ dos produtores. Neste grupo, $41 \%$ dos produtores afirmaram ter recebido várias propostas de compra de sua produção por agentes individuais ou representantes de outras empresas. Novamente, os produtores mais assediados por esses agentes são os de Santa Catarina, dos quais $68 \%$ revelaram ter recebido duas ou mais propostas de compra da produção. Para os produtores que compõem o Cluster 1, apenas $31 \%$ das propostas de compra por parte de um agente atravessador apresentam um preço superior ao que foi contratado com a firma integradora.

No grupo de produtores com menor incidência de quebra contratual, $80 \%$ dos produtores afirmaram estar satisfeitos ou totalmente satisfeitos com os preços pagos pela firma contratante da safra. Esse contentamento com os preços se reflete no percentual de $87 \%$ dos produtores desse grupo não ter quebrado o contrato com a firma integradora, vendendo toda ou parte da produção contratada. Os produtores do Cluster 1, em sua maioria (56\%), afirmaram que o rompimento do contrato com a empresa integradora é uma prática desonesta.

Apenas $2 \%$ dos produtores do Cluster 1 acreditam que a indústria não tem a preocupação de que eles façam uma boa safra e de que o tabaco colhido lhes dê um bom lucro. Quanto à questão da fidelidade com a firma contratante da safra, $94 \%$ dos produtores avaliam que esta traz benefícios para o produtor e para a indústria. Além disso, $80 \%$ dos produtores deste grupo consideram que o contrato firmado com a indústria representa um compromisso que deve ser totalmente atendido e $33 \%$ revelam que não romperiam o contrato mesmo frente à oferta de um maior preço ou melhor condição de venda.

Sobre o mercado internacional do tabaco, $95 \%$ dos produtores manifestaram possuir pouca ou nenhuma informação. Quanto ao endividamento dos produtores, apenas 3\% destes revelaram possuir dívidas com fornecedores de insumos ou no comércio local. As formas mais citadas de endividamento são com o Pronaf (47\%) e com as empresas integradoras (43\%). Pouco mais de $90 \%$ dos produtores do Cluster 1 entendem que seus investimentos específicos para a cultura do tabaco já foram recuperados. Por fim, $82 \%$ dos produtores deste cluster revelaram não ter intenção de abandonar o cultivo do tabaco.

O Cluster 2 apresenta como característica central reunir os produtores de tabaco que apresentaram maior incidência de quebra contratual na safra 2007/2008. Este cluster reúne 710 produtores, sendo 50\% do Rio Grande do Sul, 35\% de Santa Catarina e 15\% do Paraná. Quanto ao grau de instrução, $72 \%$ dos produtores possuem apenas o Ensino Fundamental incompleto. As propriedades rurais que compõem este cluster apresentam um tamanho médio de 14,4 hectares, e as lavouras de tabaco ocupam, em média, 2,9 hectares. Quanto ao tamanho das lavouras de tabaco, 43\% destas possuem área superior a 3 hectares. A maior parte (43\%) das propriedades possui área de até 10 hectares, sendo que as propriedades com área acima de 30 hectares somam apenas $8 \%$. Em relação à condição de posse da área cultivada, destaca-se que, no Cluster 2, 78\% são proprietários das terras da lavoura. Assim como no Cluster 1, em Santa Catarina esse percentual é maior, chegando a $86 \%$.

Os produtores do Cluster 2, em média, já desenvolvem essa atividade há 18 anos, sendo que apenas $10 \%$ têm uma experiência inferior a cinco anos no cultivo do tabaco e $37 \%$ estão há mais de vinte anos na atividade. Em $85 \%$ das unidades de produção deste cluster, não se verifica outra fonte significativa de renda que não seja da atividade agrícola e em $51 \%$ das unidades de produção igualmente não existe outra fonte de renda agrícola de importante significado econômico além da produção do tabaco. 
No Cluster 2, a atividade produtiva do tabaco é executada, em $48 \%$ dos casos, pelo proprietário e sua esposa e em $39 \%$ há o envolvimento de todos da família. A contratação de mão de obra externa ao núcleo familiar do produtor ocorre principalmente no período da colheita ( $38 \%$ dos casos), porém cabe destacar que neste grupo, em apenas $28 \%$ das unidades de produção, não há contratação de mão de obra externa.

Os produtores do Cluster 2, em média, possuem um relacionamento de nove anos com a firma contratante, $40 \%$ dos produtores apresentam um relacionamento de até cinco anos com essa firma e $28 \%$ revelaram ter mantido contrato, durante todo o tempo em que se dedicaram à produção de tabaco, com apenas uma empresa. Quanto à percepção sobre o SIP, 35\% acreditam que o sistema gera benefícios apenas para a indústria. Produzir tabaco além do que foi contratado com a firma integradora é uma prática relativamente comum entre os produtores desse grupo, uma vez que $59 \%$ revelaram plantar exatamente a área contratada com a indústria e outros $38 \%$ afirmaram compor suas lavouras plantando mais do que o estabelecido no contrato com a indústria.

No Cluster 2, 62\% dos produtores já haviam vendido tabaco para outras empresas que não aquela que contratou a produção. Essa parcela é ligeiramente superior entre os produtores do Rio Grande do Sul (64\%). Neste cluster, $73 \%$ dos produtores afirmaram ter recebido várias propostas de compra de sua produção por agentes individuais ou representantes de outras empresas diferentes daquela que contratou a produção. Para os produtores, $74 \%$ das propostas de compra por parte de atravessador apresentam preço superior ao que foi contratado com a firma integradora.

No grupo de produtores com maior incidência de quebra contratual, somente $36 \%$ dos produtores afirmaram estar satisfeitos ou totalmente satisfeitos com os preços pagos pela firma contratante. Esse descontentamento com os preços se reflete no percentual de $61 \%$ dos produtores deste grupo ter quebrado o contrato com a firma integradora, vendendo toda ou parte da produção contratada na safra de $2007 / 2008$. Somente $6 \%$ dos produtores consideram o rompimento do contrato uma prática desonesta.

No mesmo sentido, $11 \%$ dos produtores do Cluster 2 não acreditam que a indústria tenha a preocupação de que os produtores façam uma boa safra e de que o tabaco colhido lhes dê um bom lucro. Quanto à fidelidade com a firma contratante da safra, $22 \%$ dos produtores avaliam que esta traz benefícios somente para a indústria. Por conta disso, apenas $30 \%$ dos produtores deste grupo consideram que o contrato firmado com a indústria representa um compromisso que deve ser totalmente atendido e somente $2 \%$ dos produtores revelam que não romperiam o contrato mesmo frente à oferta de um maior preço, ou melhor condição de venda.

Sobre o mercado internacional do tabaco, igualmente ao demonstrado pelo Cluster 1 , $95 \%$ dos produtores manifestaram possuir pouca ou nenhuma informação. Quanto ao endividamento, $8 \%$ revelaram possuir dívidas com fornecedores de insumos ou no comércio local. As formas mais citadas são com o Pronaf (45\%) e com as empresas integradoras (40\%). Entre os produtores do Cluster 2, 86\% entendem que seus investimentos específicos para a cultura do tabaco já foram recuperados. Finalmente, 33\% dos produtores revelaram ter intenção de abandonar esse cultivo.

Algumas diferenças entre os clusters 1 e 2 podem ser evidenciadas. Em média, os produtores de tabaco do Cluster 2 já desenvolvem essa atividade há mais tempo, porém são menos fiéis às firmas com as quais estabelecem contratos. Isso se evidencia pelo número médio de empresas com as quais já estabeleceram contratos e pela parcela de produtores que mantiveram contrato com apenas uma firma. No Cluster 1, há uma parcela menor de mão de obra contratada e as lavouras são menores, além disso uma parcela maior dos produtores desse grupo confia nos benefícios do SIP.

No Cluster 2, a prática de formar lavouras maiores do que o contratado é mais comum, assim como a quebra dos contratos firmados com a firma integradora, prática que poucos entre 
estes produtores consideram desonesta. Este grupo é também mais assediado com propostas de compra da produção por agentes atravessadores, os quais, na maior parte das vezes, oferecem preços mais elevados que os praticados pela firma contratante da safra. A parcela de produtores insatisfeita com os preços praticados pela empresa integradora é substancialmente maior no Cluster 2, no qual os produtores, em grande parcela, não acreditam que as firmas estejam interessadas no seu bom desempenho econômico com a atividade de plantio de tabaco.

Muitos produtores do Cluster 1 acreditam que a fidelidade contratual traz benefícios tanto para eles como para a indústria, ao passo que, no Cluster 2, essa parcela é menor. Uma grande diferença entre os produtores do Cluster 1 e do Cluster 2 é percebida quanto ao entendimento destes em relação ao contrato. No primeiro grupo, o contrato é visto como algo que deve ser cumprido, enquanto no outro grupo não há esse entendimento por parte dos produtores. Disso resulta que os produtores de tabaco que se encontram no Cluster 2 são mais suscetíveis ao rompimento do contrato com a empresa integradora.

\section{DISCUSSÃO DOS RESULTADOS}

Com base nos resultados da pesquisa, é possível estabelecer uma discussão abrangente sobre as suas implicações teóricas. A racionalidade limitada, como descrita por Simon (1956, 1997, 2000), presente principalmente entre os agricultores e identificada pelo baixo nível de educação e pela forte influência do ambiente externo para a transação, age com mais força no grupo de produtores que quebram seus contratos com empresas. A quebra de contrato também é mais frequente entre os agricultores que não têm maiores ligações com as empresas e, portanto, não estão em condições de formar uma reputação positiva. Como se observa na literatura, uma reputação positiva entre os agentes (WILLIAMSON, 1985) cria laços de confiança (HAGEN; CHOE, 1998) que impõem o cumprimento de contratos e reduzem os custos de transação (WILLIAMSON, 1998). A quebra de contrato é um comportamento oportunista (WILLIAMSON, 1985) por parte dos agricultores, e essa prática é influenciada tanto pela percepção sobre os benefícios da relação com a indústria (HAGEN; CHOE, 1998; WILLIAMSON, 1998) como pela incerteza e volatilidade que percebe o ambiente em que eles realizam transações (DYER, 1996, 1997).

\section{CONSIDERAÇÕES FINAIS}

O objetivo central da pesquisa foi o de estabelecer as características socioeconômicas e os aspectos relacionais entre produtores e indústria que poderiam estar relacionadas com o comportamento oportunista configurado na quebra contratual por parte dos produtores. As informações obtidas permitiram destacar que a quebra contratual ocorre em situações especiais que reúnem os elementos que podem ser assim sintetizados:

a. maior parcela de mão de obra externa à unidade familiar de produção; menor tempo de relacionamento com a firma contratante da safra; maior rotatividade contratual com empresas integradoras;

b. menor grau de credibilidade nos benefícios decorrentes do SIP; menor grau de confiança nas intenções e objetivos da firma integradora; histórico de quebras contratuais em safras anteriores;

c. maior assédio ao produtor por parte dos agentes atravessadores; preços mais elevados oferecidos pelos atravessadores; menor grau de satisfação com os preços 
pagos pela firma contratante da safra; perspectiva de recebimento de maior preço pelo tabaco já produzido;

d. menor percepção quanto aos reflexos/restrições morais da quebra contratual; menor percepção do contrato como peça jurídica formal que estabelece compromissos entre as partes;

e. maior grau de endividamento com fornecedores de insumos e com o comércio local; maior necessidade de recuperar os capitais investidos em ativos específicos (estufas).

A análise de cluster destacou as principais características distintivas dos produtores de tabaco mais propensos à quebra contratual. Os resultados do estudo indicam algumas diferenças de comportamento quanto à quebra contratual entre os dois clusters pesquisados. Verificou-se que os produtores do Cluster 2 são mais suscetíveis a rompimentos de contratos. Nesse cluster, dos produtores pesquisados, $73 \%$ informaram que já receberam propostas de compra do seu produto de outras empresas diferentes daquela que contratou sua produção. Os produtores do Cluster 1 apresentam um grau maior de fidelidade com relação aos contratos estabelecidos. Do total dos produtores pesquisados, $94 \%$ afirmam que os contratos com as empresas compradoras geram benefícios para as duas partes, contratados e contratantes.

Os produtores que quebram contratos também são os mais assediados com propostas de compra da produção por agentes atravessadores, que oferecem preços mais elevados para a compra do tabaco que foi contratado por outra firma. Normalmente, são produtores que estão insatisfeitos com os preços praticados pela empresa integradora e que não acreditam que esta esteja interessada no bom desempenho econômico do produtor com a atividade de cultivo do tabaco. Por isso, muitos pretendem abandonar a atividade do cultivo de tabaco. Igualmente, não acreditam que a fidelidade contratual traga benefícios conjuntos para produtores e indústria. Observou-se que os produtores que quebram contratos estão atuando há mais tempo na atividade produtiva e já trocaram várias vezes de empresa integradora. Esses produtores são os que mais contratam mão de obra externa à unidade familiar e possuem dívidas com fornecedores de insumos e com o comércio local. Finalmente, destaca-se que a parcela de produtores que possui dívidas com fornecedores de insumos e com o comércio local é maior no Cluster 2, assim como a de produtores que pretendem abandonar a atividade do cultivo de tabaco no médio e no longo prazo. 


\section{REFERÊNCIAS}

ANUÁRIO Brasileiro do Fumo. Santa Cruz do Sul: Gazeta, 2007.

AREND, S. C. Famílias fumicultoras no Sul do Brasil: situação econômica dos associados à Associação dos Fumicultores do Brasil (AFUBRA). REDES: Rev. Des. Regional, Santa Cruz do Sul, v. 19, Ed. Especial, p. 118-138, 2014.

BEGNIS, H. S. M.; ESTIVALETE, V. F. B.; PEDROZO, E. A. Confiança, comportamento oportunista e quebra de contratos na cadeia produtiva do fumo no sul do Brasil. Gestão \& Produção, v. 14, n. 2, p. 311-322, 2007.

COASE, R. H. The Nature the Firm. Economica, [s.n.], p. 386-405, 1937.

DAS, T. K.; TENG, B. Betwen trust and control: developing confidence in partner cooperation in alliances. Academy of Management Review, v. 23, n. 3, p. 491-512, 1998.

Dyer, J. H. Specialized supplier networks as a source of competitive advantage: evidence from the auto industry. Strategic Management Journal, v. 17, n. 4, p. 271-291, 1996.

. Effective interfirm collaboration: how firms minimize transaction costs and maximize transaction value. Strategic Management Journal, v. 18, n. 7, p. 535-556, 1997.

FARINA, E. M. M. Q.; AZEVEDO, P. F.; SAES, M. S. M. Competitividade: mercado, estado e organizações. São Paulo: Singular, 1997.

FELTRE, C.; PAULILLO, L. F. Contribuições para a análise dos mecanismos de governança na produção rural. In: ZUIN, L. F. S.; QUEIROZ, T. R. (Coord.). Agronegócios: gestão e inovação. São Paulo: Saraiva, 2006. p. 91-126.

FIANI, R. Teoria dos Custos de Transação. In: KUPFER, D.; HASENCLEVER, L. Economia Industrial. 2. ed. Rio de Janeiro: Campus, 2013.
Hagen, J. M.; Choe, S. Trust in Japanese interfirm relations: institutional sanctions matter. The Academy of Management Review, v. 23, n. 3, p. 589-600, 1998.

Gulati, R. Does familiarity breed trust? The implications of repeated ties for contractual choice in alliances. Academy of Management Journal, v. 38, n. 1, p. 85-112, 1995.

HAIR, J. F. et al. Análise multivariada de dados. 5. ed. Porto Alegre: Bookman, 2005.

HAYEK, F. A. The use of knowledge in society. American Economic Review, v. 35, n. 4, p. 519530, 1945.

Hill, C. W. L. Cooperation, opportunism, and the invisible hand: implications for transaction cost theory. The Academy of Management Review, v. 15, n. 3, p. 500-513, 1990.

Kale, P.; Singh, H.; Perlmutter, H. Learning and protection of proprietary assets in strategic alliances: building relational capital. Strategic Management Journal, v. 21, n. 3, p. 217-237, 2000.

LIVATO, M.; BENEDICTO, G. C. Uma proposta dos canais de distribuição como vantagem competitiva no varejo de alimentos. Revista de Administração da UFSM, v. 3, n. 3, p. 361-374, 2010.

MARCONATTO; D. A. B.; ESTIVALETE, V.; PEDROZO, E. P. Confiança, controles e riscos em relacionamentos interorganizacionais no âmbito de cadeias de suprimento. Revista de Administração da UFSM, v. 7, n.4, p. 700-718, 2015.

MORVAN, Y. Filière de production: fondementes d'economie industrielle. Paris: Economica, 1985.

Nooteboom, B.; Berger, H.; Noorderhaven, N. $\mathrm{G}$. Effects of trust and governance on relational risk in alliances. Academy of Management Journal, v. 40, n. 2, p. 308-338, 1997. 
Parkhe, A. Strategic alliance structuring: a game theoretic and transaction cost examination of interfirm cooperation. Academy of Management Journal, v. 36, n. 4, p. 794-829, 1993.

PINHEIRO, A. C.; SADDI, J. Direito, economia e mercados. Rio de Janeiro: Campus, 2006.

PIRANI, S. L.; CUNHA, C. R. A formação da confiança: um estudo no Pool da UNIBRASPE. Revista de Administração da UFSM, v. 3, n. 3, p. 375-392, 2010.

REZENDE, C. L.; ZYLBERSZTAJN, D. Quebras contratuais e dispersão de sentenças. Revista Direito GV, v. 7, n, 1, p. 155-176, 2011.

SIMON, H. A. Rational choice and the structure of the environment. Psychological Review, v. 63, p. 129-138, 1956.

Administrative behavior. 4. ed. New York: The Free Press, 1997.

Barriers and bounds to rationality. Structural Change and Economic Dynamics, v. 11, p. 243-253, 2000.

WILLIAMSON, $\mathrm{O}$. The economic institutions of capitalism. New York: The Free Press, 1985.

Comparative Economic Organization: the analysis of discrete structural Alternatives. Administrative Science Quarterly, vol. 36, p. 269-296, 1991.

The mechanisms of governance. New York: Oxford University Press, 1996.

. The Institutions of Governance. American Economic Review, v. 88, n. 2, p. 7579, 1998.

The Theory of the Firm as Governance Structure: from choice to contract. 2002. Disponível em: <http://groups.haas.berkeley. edu/bpp/oew/papers.htm>. Acesso em: 12 jul. 2008.

ZYLBERSZTAJN, D. Economia das organizações.
In: ZYLBERSZTAJN, D.; NEVES, M. F. (Org.). Economia e gestão dos negócios agroalimentares: indústria de alimentos, indústria de insumos, produção agropecuária, distribuição. São Paulo: Pioneira, 2000. p. 2338. 